\title{
Identificando Compromissos Epistemológicos, Ontológicos e Axiológicos em Falas de Licenciandos Quando Discutem uma Questão Sociocientífica
}

\author{
Identifying Epistemological, Ontological and Axiological \\ Commitments in Pre-Service Chemistry Teachers' Speeches as \\ They Discuss a Socio-Scientific Issue
}

\section{Bruna H. S. Bezerra e Edenia M. R. do Amaral}

\begin{abstract}
Resumo: Questões com relevância social e científica favorecem a abordagem de conceitos científicos associados a situações vivenciadas pelos sujeitos e podem promover a articulação entre diferentes perspectivas e visões que eles expressam sobre essas questões. Neste trabalho analisamos a heterogeneidade de modos de pensar que emergiram na fala de licenciandos de química, quando foi abordada uma Questão SocioCientífica (QSC) sobre combustíveis e impactos ambientais, em um minicurso. Foram analisadas ideias mobilizadas por um grupo de licenciandos na discussão sobre diesel, etanol e gasolina, considerando, entre outros aspectos, a capacidade de produção de energia, entalpia, preço, rendimento e impactos ambientais que estão implicados em processos de obtenção e uso desses combustíveis. Textos de apoio foram disponibilizados aos licenciandos, que deveriam tomar uma decisão sobre um tipo de automóvel a ser adquirido. Transcrições de falas e registros escritos foram analisados e diagramas temáticos foram desenhados, buscando identificar e representar relações semânticas estabelecidas entre itens temáticos usados pelos licenciandos. Ao longo das discussões no grupo, verificamos uma aproximação entre ideias sobre combustíveis e energia (fontes e produção) e, dessa forma, identificamos compromissos epistemológicos, ontológicos e axiológicos associados a modos de pensar energia como algo material, funcional ou agente de transformação. A decisão do grupo foi tomada a partir de uma negociação articulada de fatores que envolviam alguns desses compromissos.
\end{abstract}

Palavras-chave: Perfil Conceitual. Questões Sociocientíficas, Energia e Combustíveis.

\begin{abstract}
Issues with social and scientific relevance favor the approach of scientific concepts associated with situations experienced by individuals and can promote the articulation among different perspectives and views that they express on these issues. In this work, we analyzed the heterogeneity of modes of thinking that emerged in pre-service chemistry teachers' speeches, when a Socio-Scientific Issue (SSI) on fuels and environmental impacts was proposed in a short course. We analyzed the ideas mobilized by a group of pre-service chemistry teachers from discussions on diesel, ethanol and gasoline, considering, among other aspects, calorific value, enthalpy, price, yield of motor fuel and environmental impacts that are implicated in processes of obtaining and using of these fuels. Supporting texts were made available to the pre-service chemistry teachers, who should make a decision on a type of car to be purchased. Transcripts of speeches and written registers were analyzed, and thematic diagrams were designed, seeking for identifying and representing semantic relationships between thematic items used by the pre-service chemistry teachers. Throughout the discussions in the group, we could realize an approximation between ideas about fuels and energy (sources and production) and, in this way, we were able to identify epistemological, ontological and axiological commitments associated with modes of thinking on energy as something material, functional or agent of transformation. The decision of the group was taken from an articulated negotiation of factors that involved some of these commitments.
\end{abstract}

Keywords: Conceptual Profile. Socio-Scientific Issues. Energy and Fuels.

Bruna Herculano da Silva Bezerra (bruna.herculano4@ gmail.com) concluiu Licenciatura em Química na Universidade Federal Rural de Pernambuco (UFRPE), Mestrado em Ensino de Ciências (Programa de Pós-Graduação em Ensino de Ciências (PPGEC)-UFRPE) e Doutorado em Ensino de Ciências e Matemática no PPGEC-UFRPE. Atualmente é professora da Unidade Acadêmica de Serra Talhada (UAST) da UFRPE. Serra Talhada, PE - BR. Edenia Maria Ribeiro do Amaral (edeniamramaral@gmail.com) concluiu Engenharia Química e Mestrado em Ciências e Tecnologias Nucleares na Universidade Federal de Pernambuco (UFPE), Doutorado em Educação na Universidade Federal de Minas Gerais (UFMG), é docente permanente no PPGEC-UFRPE e atua no Curso de Licenciatura em Química da UFRPE, campus Recife. Recife, PE - BR.

Recebido em 31/08/2018, aceito em 25/10/2018

A seção "Cadernos de Pesquisa" é um espaço dedicado exclusivamente para artigos inéditos (empíricos, de revisão ou teóricos) que apresentem profundidade teórico-metodológica, gerem conhecimentos novos para a área e contribuições para o avanço da pesquisa em Ensino de Química. 
Documentos curriculares e pesquisas vêm há algum tempo apontando para a necessidade de abordagens articuladas entre conteúdos científicos e realidades vividas pelos sujeitos, de forma a significar a aprendizagem da ciência escolar. Entre diferentes perspectivas desenvolvidas nessa direção - projetos didáticos, abordagem ao cotidiano, contextualização, estudos de casos, situações problemas, e outros - o uso didático de questões com relevância social e científica tem tido destaque em pesquisas sobre educação em ciências (Galvão e Reis, 2008; Sadler e Zeidler, 2005; Sadler, 2011; e Martínez Pérez e Carvalho, 2012). Questões sociocientíficas emergem no contexto das discussões sobre as relações entre Ciência, Tecnologia e Sociedade e ganham autonomia enquanto estratégias ou recursos que podem instrumentalizar as ações no processo de ensino e aprendizagem de ciências (Zeidler et al., 2005).

Para Sadler (2004), Questões SocioCientíficas (QSC) são questões sociais controversas que têm relações conceituais e/ ou processuais com a ciência e podem ser caracterizadas como problemas abertos, sem soluções claras, ou que tendem a ter múltiplas soluções plausíveis. Segundo o autor, respostas ou soluções para QSC podem ser informadas pelos princípios da ciência, teorias e dados, no entanto, não podem ser totalmente determinadas pelas considerações científicas (Sadler, 2011). Pode-se considerar que as QSC trazem dilemas e problemas que para serem resolvidos sofrem influência de diversos fatores: sociais, econômicos, políticos, éticos e outros.

A abordagem de QSC no ensino de ciências busca especificamente capacitar os estudantes a considerarem como decisões tomadas a respeito de questões sociais que envolvem o conhecimento científico refletem, por um lado, os princípios e qualidades morais da virtude que englobam suas próprias vidas, e por outro, o mundo físico e social ao seu redor (Sadler, 2004). Assim, uma educação científica pautada na abordagem de QSC pode mobilizar conhecimentos científicos e envolver questões éticas na construção de julgamentos morais sobre tópicos ou situações. Em contextos de ensino e aprendizagem, isso pode ocorrer a partir do estabelecimento de interações sociais entre os sujeitos para a produção de discursos em um processo dialógico de expressão de sentidos e compartilhamento de significados.

Para Ratcliffe e Grace (2003), QSC são questões que têm uma base científica e trazem problemáticas que podem ser avaliadas quanto às suas potenciais implicações e impactos causados na sociedade, a partir da mobilização do conhecimento científico de diferentes áreas. Os autores propõem um conjunto de aspectos que podem caracterizar uma QSC: [1] Podem ser abordadas por diferentes ângulos e são compreendidas frequentemente nas fronteiras de conhecimentos científicos de diferentes áreas; [2] Envolvem formar opiniões, tomar decisões em nível pessoal ou social; [3] São frequentemente relatadas pela mídia, contudo é comum a apresentação de problemas com base "nas intenções do comunicador"; [4] Tratam de informações que trazem conflitos e incompletudes inerentes às evidências e relatórios científicos; [5] Abordam problemáticas de dimensões local, nacional e global envolvendo aspectos políticos e sociais concomitantes; [6] Envolvem alguma análise de custo e benefício em que o risco implica em questões de valores; [7] Podem envolver considerações sobre o desenvolvimento sustentável; [8] Envolvem valores e raciocínio ético; [9] Podem exigir alguma compreensão de probabilidade e risco; [10] São frequentemente tópicos que se relacionam com a vida cotidiana. Nessa perspectiva, a abordagem de QSC no ensino de ciências possibilita tratar de implicações sociais e ambientais da ciência e tecnologia, e também refletir sobre visões pessoais dos estudantes e seus sistemas de crenças.

Quando abordamos QSC, trazemos para ou constituímos na sala de aula contextos que não necessariamente fazem parte do saber e fazer escolar clássico ou institucionalizado, mas que se referem a realidades vivenciadas pelos sujeitos e, muitas vezes, não estão contempladas nos conteúdos escolares das disciplinas. De acordo com Rodrigues e Mattos (2007, p. 24):

[...] trazer (para a sala de aula) um contexto de fora da escola (exofórico), é trazer não só os problemas, soluções e conhecimentos deste contexto, mas é trazer também todas as motivações, valores e fins das atividades que se desenvolvem nele, ou seja, trazer um contexto é trazer suas dimensões epistemológicas, ontológicas e axiológicas.

Na abordagem de QSC no ensino e aprendizagem de ciências, problemáticas, soluções possíveis ou plausíveis, decisões e conhecimentos estão associados a um ou mais contextos diferentes, que favorecem a emergência de concepções ou representações que os sujeitos têm e que não necessariamente se alinham com uma visão científica do mundo. Dessa forma, o discurso produzido em sala de aula aponta para uma heterogeneidade de pensamento, quando os estudantes discutem sobre situações contextualizadas e/ou questões de natureza científica e social. Algumas pesquisas sugerem que frequentemente o público em geral (Pompe et al., 2005) e licenciandos de graduação (Halverson et al., 2009) ignoram ou negligenciam o conhecimento científico implicado em questões sociocientíficas, e processos de tomada de decisão são afetados por fatores diversos que não necessariamente envolvem ideias ou modelos científicos. Isso sugere que pode ser complexa a tarefa de tornar relevantes explicações científicas, quando valores e subjetividades se tornam predominantes na discussão de QSC, em sala de aula. Isso aponta para dificuldades na articulação de diferentes modos de pensar ou perspectivas sobre as problemáticas em foco.

$\mathrm{Na}$ literatura em ensino de ciências, vemos ressaltado que o uso da evidência científica, isto é, a dimensão epistemológica do conceito é um critério empregado com dificuldade para sustentar os processos argumentativos dos licenciandos (Sadler e Zeidler, 2005). Os autores sugerem que essa lacuna está relacionada com a dificuldade de o estudante articular conceitos científicos com situações concretas. Para Rodrigues e Mattos (2007), o processo de apropriação e de formação de 
um conceito deve envolver a sua aplicação em situações reais, o que demanda articulações complexas de diferentes concepções e ideias vinculadas aos contextos vivenciados pelos sujeitos. Diversas pesquisas têm demonstrado que um conceito não tem apenas uma única representação, mas um perfil de representações com características não só epistemológicas, mas também ontológicas e axiológicas (Mortimer, 2000; Sodré, 2008; Sodré e Mattos, 2013; Bastos e Mattos, 2009; Mortimer et al., 2014).

Essas considerações apontam para a necessidade de desenvolver estudos sobre a aprendizagem dos conceitos científicos considerando a existência de uma heterogeneidade do pensamento, na qual podem ser identificadas dimensões epistemológicas, ontológicas e axiológicas na compreensão de ideias e modelos da ciência. Esse tipo de enfoque é feito no âmbito da teoria do perfil conceitual (Mortimer et al., 2014), e neste trabalho, buscaremos articular as discussões sobre a abordagem de QSC a princípios constituintes dessa teoria.

\section{Articulando QSC e Perfil Conceitual no Ensino de Ciências}

A teoria do perfil conceitual tem como pressuposto a ideia de que um indivíduo apresenta diferentes formas de ver e conceituar o mundo e diferentes modos de pensar podem ser mobilizados por este indivíduo em diferentes contextos. A heterogeneidade do pensamento pode ser compreendida considerando que, em qualquer cultura e em qualquer indivíduo, existem diferentes tipos de pensamento verbal, não só uma forma única, homogênea de pensar (Tulviste e Hall, 1991). A heterogeneidade do pensamento verbal pode ser representada por diferentes modos de pensar, considerados a partir de significados socialmente construídos e estabilizados atribuídos a diferentes experiências vivenciadas pelos sujeitos (Mortimer $e t$ al., 2014). Cada modo de pensar pode ser modelado como uma zona de um perfil conceitual. Dessa forma, perfis conceituais se constituem como modelos representativos da heterogeneidade do pensamento verbal, que estruturam diferentes modos de pensar em zonas caracterizadas por compromissos epistemológicos, ontológicos e axiológicos distintos.

Mortimer et al. (2014) apontam que a teoria do perfil conceitual toma por base uma síntese coerente de vários pressupostos consolidados na literatura: a perspectiva sociocultural - que possibilita a compreensão de perfis conceituais como ferramentas para estruturação e gênese dos diferentes modos de pensar sobre um mesmo conceito, que estão associados às experiências e as interações sociais e culturais dos sujeitos; a teoria da linguagem do círculo de Bakhtin (1929) - como base para a compreensão sobre a dialogicidade e intersubjetividade presentes na produção de enunciações; a teoria de Vygotsky (1962) sobre o desenvolvimento das funções mentais superiores, como base para a investigação da aprendizagem; e a análise das interações discursivas (Mortimer e Scott, 2002) para pesquisa da dinâmica discursiva em sala de aula, o que possibilita a análise de formas de falar associadas a modos de pensar (Mortimer e Wertsch, 2003). Este último aspecto está fortemente relacionado ao pressuposto de que aprender ciência implica na aquisição e domínio da linguagem social da ciência escolar, que podem ser constituídos a partir da produção de discursos em sala de aula (Mortimer e El-Hani, 2013).

Na literatura, podem ser encontrados perfis conceituais propostos em diferentes áreas do conhecimento como a Biologia, Física e a Matemática, especificamente em Química, podemos citar alguns deles: átomo e de estados físicos da matéria (Mortimer, 1995; Mortimer, 2000), molécula (Mortimer, 1997; Mortimer e Amaral, 2014); calor (Amaral e Mortimer, 2001; Araújo e Mortimer, 2013); entropia (Amaral e Mortimer, 2004); substância (Silva, 2011; Silva e Amaral, 2013, Sabino e Amaral, 2018); energia (Simões Neto, 2016); Química (Freire, 2017) e outros. Trabalhos recentes têm investigado o uso de perfis conceituais propostos como ferramentas para o planejamento e análise do ensino e aprendizagem em sala de aula, com a proposição de estratégias e atividades didáticas desenhadas a partir de zonas desses perfis (ver Silva e Amaral, 2006; Sepúlveda, 2009; Sabino, 2015; Sabino e Amaral, 2015; Sabino e Amaral, 2018; Simões Neto et al., 2015; entre outros). Neste trabalho, buscaremos identificar compromissos epistemológicos, ontológicos e axiológicos associados a diferentes modos de pensar identificados em discursos produzidos por licenciandos de química, quando discutem uma questão sociocientífica, considerando zonas de um perfil conceitual. Dessa forma, pretendemos aprofundar a compreensão sobre as aprendizagens construídas no trabalho com QSC, em sala de aula.

A abordagem de QSC pode possibilitar a articulação de dimensões sociais, culturais, políticas, ideológicas e históricas da atividade humana, a partir da formação escolar. Com isso, ao trabalhar com QSC, o professor não lida apenas com conhecimento científico, mas, com diversos modos de pensar que emergem dos contextos constituídos em situações de estudo. Diferentes modos de pensar estruturados em zonas de um perfil conceitual apontam para compromissos epistemológicos, ontológicos ou axiológicos distintos que podem estar implicados nas ideias expressadas pelos licenciandos. Com isso, buscamos trabalhar com aproximações entre a teoria do perfil conceitual e a abordagem de QSC na sala de aula, enfatizando principalmente a relevância que os contextos ganham para a aprendizagem de conceitos e modelos científicos. Adotamos a perspectiva de que um contexto se constitui em situações de ensino e aprendizagem, a partir da complexificação da realidade e suas representações, sendo considerado como uma construção social, histórica e cultural compartilhada por meio das interações humanas e da linguagem (Rodrigues e Mattos, 2007). Dessa forma, diferentes modos de pensar associados a contextos diversos e modelados por zonas de um perfil conceitual poderão emergir na discussão das múltiplas dimensões implicadas em uma questão sociocientífica. Neste trabalho, analisamos a abordagem de uma QSC sobre combustíveis e impactos ambientais, considerando 
aspectos como a capacidade de produção de energia, preço, rendimento e impactos ambientais envolvidos em processos de obtenção e uso de três combustíveis - gasolina, etanol e diesel. Foram promovidas discussões de aspectos científicos, sociais, econômicos e ambientais relativos à escolha de um combustível para abastecer automóveis, no âmbito de um minicurso ofertado para licenciandos em química.

A caracterização de compromissos epistemológicos, ontológicos e axiológicos associados a diferentes modos de pensar foi feita principalmente considerando zonas de um perfil conceitual proposto para o conceito de energia (Simões Neto, 2016). Para o perfil conceitual de energia foram propostas seis zonas representativas de diferentes modos de pensar sobre o conceito: energia como algo espiritual ou místico - zona que reúne ideias associadas a contextos espirituais, místicos e/ou esotéricos; energia funcional/utilitarista - são consideradas ideias que circulam no senso comum ou contexto escolar, em que prevalecem a utilidade e a função da energia em processos e fenômenos; energia como movimento - a energia é compreendida de forma associada ao movimento dos corpos (contexto científico), ou como algo que pode produzir vento, velocidade, exercícios e esforço físico (contextos diversos); energia como algo material - a energia é vista como algo material ou quase material que pode ser armazenada; energia como agente causal das transformações - a energia é vista como algo que pode causar transformações físicas, químicas e bioquímicas numa visão determinística causal; e por fim, energia como grandeza que se conserva - relacionada a conceitos científicos de conservação e degradação de energia (Simões Neto, 2016; Simões Neto e Amaral, 2017).

Tomando por base o perfil conceitual de energia, estamos considerando uma abordagem na qual questões sobre energia subjazem às análises sobre fontes, composição, produção e uso de combustíveis. Com isso, buscamos identificar compromissos epistemológicos, ontológicos e axiológicos que emergiram no processo de tomada de decisão desencadeado pela QSC proposta. Para Rodrigues e Mattos (2007), a dimensão epistemológica se refere ao "como" conhecemos um determinado objeto. Por exemplo, o conceito de energia pode ser compreendido a partir de uma perspectiva empirista ou racionalista sejam elas clássicas, relativísticas ou quânticas. Nessa dimensão, estão circunscritas diversas interpretações dadas aos conceitos científicos a partir de diferentes correntes filosóficas. A dimensão ontológica se refere à natureza dos objetos, neste caso, aponta para categorias ontológicas às quais os conceitos científicos são associados - material, eventos e abstrações (Chi, 1992) - na busca de responder "o que" é o objeto. A dimensão axiológica se refere aos valores atribuídos a determinados objetos e procura responder ao "por quê" das escolhas e fins associados aos mesmos. No nosso caso, diz respeito às motivações e intenções com as quais um conceito é ou não utilizado pelo indivíduo. Essas dimensões orientam o estudo sobre a polissemia dos conceitos e as diversas representações e significados que poder ser conferidos a eles dependendo do contexto de uso.

\section{Aspectos Metodológicos}

Esta pesquisa adotou uma abordagem qualitativa com caráter interpretativo e descritivo quanto ao método, à forma e aos objetivos aos quais se propõe investigar, considerando como fonte direta de dados o ambiente natural no qual se realiza, sendo os sujeitos pesquisados e as suas subjetividades uma preocupação investigativa (André, 2010). Os dados foram construídos no âmbito do minicurso intitulado "Combustíveis e impactos ambientais: construindo relações entre contextos e perfis conceituais", ofertado no IV Encontro de Química e Formação Docente, promovido pelo Curso de Licenciatura em Química de uma universidade pública no estado de Pernambuco.

O minicurso foi proposto e desenvolvido pelo grupo de pesquisa do qual as autoras fazem parte, no qual foram discutidas e elaboradas QSC a partir de temas envolvendo diferentes situações de obtenção e uso de combustíveis diversos - gasolina e outros combustíveis (tema 1), etanol (tema 2), gás natural e biodiesel (tema 3) - e uma QSC que tratava da obtenção e uso de energia eólica (tema 4). O minicurso teve 4 horas de duração e contou com a participação de cerca de 40 licenciandos de diferentes períodos do curso, que foram divididos em 6 grupos - dois grupos trabalharam com o tema 1, dois grupos com o tema 2, um grupo com o tema 3 e um grupo com o tema 4. Em cada grupo, atuaram pelo menos dois monitores do grupo de pesquisa. Para este trabalho, fizemos a análise da discussão de um grupo composto por cinco licenciandos, que cursavam $3^{\circ}$, $6^{\circ}$ e $7^{\circ}$ períodos da licenciatura, e que discutiram o tema 1. Para o tema 1, foi proposta uma QSC intitulada "Etanol, gasolina ou diesel: limites, riscos e benefícios no uso desses combustíveis," considerando aspectos da natureza química, produção, custos desses produtos e impactos ambientais que podem causar.

As atividades no minicurso foram organizadas nas seguintes etapas: (a) Aplicação de um questionário para traçar um perfil e fazer levantamento de concepções dos licenciandos; (b) Apresentação dos objetivos do minicurso, e leitura de todas as QSC envolvidas nos 4 temas - em cada tema, foram propostas questões e solicitadas decisões a serem tomadas e para nortear a discussão dos grupos, foram disponibilizados textos e infográficos; (c) Discussão dos temas e textos pelos grupos e elaboração de respostas escritas para as questões propostas, em fichas disponibilizadas, buscando justificar a decisão tomada pelo grupo; (d) Apresentação das respostas e decisões tomadas por cada grupo a todos os participantes. As apresentações dos grupos foram videogravadas e as discussões nos pequenos grupos foram gravadas em áudio, as respostas ao questionário e as fichas de respostas preenchidas foram recolhidas como registros para posterior análise. Neste trabalho, é apresentada a análise de transcrições de áudio e vídeo gravados durante as discussões de um grupo (5 licenciandos) sobre o tema 1.

Para a identificação de modos de pensar, foram analisadas formas de falar dos licenciandos, a partir da semiótica social, com a construção de diagramas de padrões temáticos (Lemke, 
1997). Com isso, buscamos caracterizar sentidos e significados atribuídos a conceitos ou termos, a partir de relações semânticas estabelecidas pelos licenciandos para itens temáticos. Diagramas temáticos foram propostos por Lemke (1997) para representar graficamente o padrão temático produzido por um indivíduo ou grupo de indivíduos nas interações discursivas em sala de aula ou em discursos produzidos sobre um tópico da ciência. De acordo com o autor, em um diagrama temático, termos são designados como itens temáticos, que podem ser abstratos, conceituais, e expressos por uma ou mais palavras. Esses itens temáticos estão conectados uns aos outros por meio de relações semânticas. As relações semânticas descrevem como os significados atribuídos a pelo menos dois itens temáticos se encontram relacionados quando eles são usados para falar sobre um tópico particular, e constituem uma generalização das diferentes formas gramaticais de expressar esta relação (Lemke, 1997; Sepulveda et al., 2011; Rodrigues e Pereira, 2015). Lemke (1997) propõe uma lista de relações semânticas mais comuns e o modo como são nomeadas em diferentes teorias semânticas e gramaticais. No Quadro 1 apresentamos algumas das relações semânticas propostas pelo autor.

Neste trabalho, itens temáticos e relações semânticas foram identificados nas falas dos licenciandos para a construção de diagramas temáticos, a partir dos quais analisamos diferentes modos de pensar, considerando compromissos específicos que emergem na discussão sobre a QSC e no processo de tomada de decisão. Como colocado anteriormente, tomamos como referência alguns pressupostos da teoria do perfil conceitual
(Mortimer et al., 2014), para identificar compromissos epistemológicos, ontológicos e axiológicos que estão implicados em diferentes modos de pensar, estruturados em zonas de perfis conceituais.

\section{Análise das Interações Discursivas: Caracte- rizando Modos de Pensar e Formas de Falar que Emergem na Abordagem de QSC}

Após responderem ao questionário inicial, os 5 licenciandos foram convidados a trabalhar com a seguinte situação:

"Historicamente, o petróleo tem sido a matéria-prima mais utilizada como fonte de combustível. Porém, como é um recurso não renovável, as reservas dessa matéria-prima sofrem ameaças de esgotamento. Atualmente, o mercado automobilístico oferece opções de veículos que se movem com diferentes tipos de combustíveis. Joaquim foi a uma concessionária e, entre as opções para compra de um carro, havia um carro com motor flex e outro movido a diesel, além dos carros movidos a gasolina. Construa respostas para as questões abaixo: Qual a melhor escolha para Joaquim? E por quê? Que fatores devem ser levados em consideração no momento da compra de um carro? O etanol e o diesel são combustíveis que podem substituir a gasolina? Ao procurar novas fontes de energia e novos combustíveis, quais fatores deverão ser levados em conta?".

Quadro 1: Algumas relações semânticas entre itens temáticos propostas por Lemke (1997)

\begin{tabular}{|c|c|}
\hline Tipos de relação semântica & Classificação e descrição \\
\hline \multirow{3}{*}{ Relações Nominais } & $\begin{array}{l}\text { Atributiva: atributo/portador ou atributo/coisa que se refere a características descritivas ou qualificadoras } \\
\text { do nome. }\end{array}$ \\
\hline & $\begin{array}{l}\text { Classificadora: classificador/coisa - refere-se a uma característica ou um tipo que identifica uma subclasse } \\
\text { de uma classe principal. }\end{array}$ \\
\hline & $\begin{array}{l}\text { Quantificadora: quantificador/coisa que se refere a características quantitativas que podem ser expressas } \\
\text { por números, e podem ser contadas. }\end{array}$ \\
\hline \multirow{4}{*}{ Relações Taxionômicas } & Mostra: mostra/tipo - referente a um exemplo individual do tipo ou classe. \\
\hline & $\begin{array}{l}\text { Hiponímia: classe subordinada/classe supraordenada, subconjunto/conjunto e conjunto/superconjunto - } \\
\text { refere-se ao nome de uma categoria que cabe dentro de alguma categoria mais geral. }\end{array}$ \\
\hline & Sinonímia: sinônimo/sinônimo que se refere a expressões com o mesmo significado em um contexto. \\
\hline & Antonímia: antônimo/antônimo - que se refere a expressões com significados distintos em um contexto. \\
\hline \multirow{4}{*}{ Relações de Transitividade } & Agente: agente/processo que se refere à causa ou ao responsável por um processo. \\
\hline & Meta: processo/meta - refere-se a uma entidade que se faz objeto da ação, ou que atua sobre ele. \\
\hline & Paciente: paciente/processo que se refere à entidade em relação a qual o processo ocorre. \\
\hline & Identificação: identificado/identificador - refere-se a expressões que identificam ou caracterizam o objeto. \\
\hline \multirow{4}{*}{ Relações Circunstanciais } & Localização: localização/localizado - expressa a relação espacial de entidades ou processos. \\
\hline & Material: matéria/processo - expressa a matéria e/ou o material envolvidos no processo. \\
\hline & $\begin{array}{l}\text { Forma: forma/processo que se referente à forma, à maneira, meios/instrumentos pelos quais ocorre o } \\
\text { processo. }\end{array}$ \\
\hline & Razão: processo/razão - expressa a causa, o propósito, a razão do processo. \\
\hline
\end{tabular}

Fonte: Lemke (1997). 
Considerando os aspectos apontados por Ratcliffe e Grace (2003) como características de QSC, a situação proposta aos licenciandos se caracteriza como um QSC porque: (a) pode ser abordada por diferentes ângulos (científico, social, ambiental, econômico, ético) e compreendida nas fronteiras de conhecimentos científicos de diferentes áreas; (b) os questionamentos envolvem formar opiniões, tomar decisões em nível pessoal ou social, e implicam em reflexões sobre a utilização dos combustíveis e seus impactos sociais e ambientais; (c) leva os sujeitos a avaliar preços dos combustíveis, custos e impactos ambientais da sua produção; (d) envolve fatos que são frequentemente relatados pela mídia e estão presentes em propagandas comerciais, apontando vantagens e desvantagens de diferentes tipos e rendimentos de motores e preços de combustíveis; (e) a questão pode ser tratada tanto considerando a dimensão local - o preço dos combustíveis na cidade, a escolha pessoal dos envolvidos quando abastecem seus veículos e os impactos locais dessa decisão - quanto considerar as dimensões nacional e global: produção dos combustíveis, impactos sociais e ambientais da produção e da utilização de combustíveis em veículos motores, aspectos políticos e sociais relacionados com a produção e comercialização de combustíveis; (f) as respostas para as questões e a decisão dos licenciandos implicam em análise de custo e benefício, de riscos, e envolvem valores e raciocínio ético.

A situação apresentada se consolida como uma QSC, ao envolver os licenciandos na discussão de questões que promovem interação dialógica, de forma que todos podem expressar suas posições individuais e ouvir a posição dos colegas na busca de construir argumentos para uma tomada de decisão pelo grupo (Driver et al., 2000). Dessa forma, os licenciandos lidam com evidências e conflitos que envolvem a QSC considerando os aspectos científicos entre outros aspectos a serem considerados, quando desenvolvem seus pontos de vista imprimindo valor ao discurso produzido em sala de aula. A importância do discurso produzido em sala de aula no desenvolvimento do raciocínio moral tem sido amplamente demonstrado em pesquisas na literatura (ver Guimarães et al., 2010; Guimarães, 2011; Sadler e Zeidler, 2005), considerando que as interações discursivas podem oferecer uma oportunidade para os sujeitos reverem suas crenças, seus pontos de vista e modos de pensamento com relação aos processos estudados. De acordo com Zeidler et al. (2005), a abordagem de QSC além de proporcionar a produção de discursos, pode enfatizar o papel crucial que este desempenha em sala de aula, nas interações entre os pares, e seu impacto nos modos de pensar dos estudantes.

Com a situação apresentada, buscamos identificar os conhecimentos mobilizados pelos licenciandos nas possíveis justificativas para a decisão sobre o carro a ser adquirido. Havia a expectativa de que diferentes formas de falar sobre conceitos de substância, calor, energia e outros pudessem emergir nas falas dos licenciandos. Analisamos as interações discursivas entre os licenciandos a partir de três episódios (E1, E2 e E3) - o primeiro (E1), extraído do momento em foi feita a leitura da QSC e dos textos complementares seguida da discussão da problemática pelo grupo. O segundo episódio (E2) foi extraído do momento em que as ideias iniciais foram retomadas, negociadas e o grupo tomou uma decisão consensual. E, finalmente, fizemos a análise da apresentação que o grupo fez a todos os participantes do minicurso, sobre a QSC, a discussão e a decisão feitas no grupo, no episódio 3 (E3).

Em cada episódio, nomeamos a fala dos licenciandos como L1, L2, L3, L4 e L5, a dos monitores que mediaram a discussão, como M1 e M2, e os enunciados foram subdivididos em turnos de falas. Os episódios foram escolhidos por apresentar "um conjunto de enunciados que cria um contexto [...]" (Amaral e Mortimer, 2006, p. 257), e algumas ideias relevantes para a análise foram destacadas em negrito para que itens temáticos fossem identificados posteriormente.

No episódio 1, depois da leitura da QSC, os licenciandos utilizaram ideias do senso comum para justificar uma escolha aligeirada pela compra do carro de motor flex - por exemplo, eles mencionaram: a possibilidade de escolha de um ou outro combustível sem explicitar características dos combustíveis usados em um motor do tipo flex ("L2 - diversidade de opção de combustíveis..."); mencionaram ser um tipo de carro que produz menor impacto ambiental e trazer a possibilidade de abastecimento a um custo menor ( $\mathrm{L} 1$ - O álcool é mais barato que a gasolina). De uma forma geral, na discussão inicial, analisada a partir do episódio 1 , os licenciandos pareceram à vontade para expressar ideias que circulam no senso comum e, dessa forma, aspectos científicos, ambientais e econômicos foram discutidos superficialmente. Nessa perspectiva, consideramos que inicialmente os licenciandos não fizeram um esforço de análise da QSC nos seus diferentes aspectos, e as ideias foram apresentadas de forma pouco comprometida com a construção de uma justificativa fundamentada para a escolha que o grupo iria fazer. Isso sugere que a situação colocada para discussão não promove o engajamento de forma imediata ou automática, é necessário que sejam adotadas estratégias para fundamentar e promover os debates. No caso do minicurso, eles foram solicitados a ler textos sobre as características físico-químicas dos combustíveis, processos de produção e impactos ambientais, e preencher fichas com várias questões.

Ao longo das discussões no grupo, ideias inicialmente vagas foram sendo enriquecidas com a consideração de outros aspectos que envolviam a situação proposta - matéria-prima (fonte de energia), rendimento, poder calorífico, entalpia de combustão, entre outros. Os licenciandos passaram a buscar no texto de apoio argumentos mais consistentes que justificassem uma escolha a ser feita pelo grupo. Apresentamos um trecho do episódio 2, no qual são mostrados alguns desses aspectos.

Nesse trecho do episódio 2, verificamos que a discussão envolve tanto ideias vindas das percepções e visões dos licenciandos quanto aquelas apresentadas nos textos, e diferentes pontos de vista são mobilizados. É interessante apontar que alguns sentidos atribuídos ao uso dos diferentes combustíveis 
Trecho do episódio 2: Discussão sobre diversos fatores considerados para a decisão do grupo

\begin{tabular}{|c|c|}
\hline 1 & $\begin{array}{l}\text { L3 - Vamos! Quais fatores devem ser levados em consideração no momento da compra, de acordo com o texto? Toda aquela questão, } \\
\text { tipo: dos impactos ambientais, do preço e do rendimento do motor, poder calorífico e entalpia de combustão. Só que aí Joaquim } \\
\text { não iria pensar em algumas coisas né? }\end{array}$ \\
\hline 2 & M2 - Com certeza! \\
\hline 3 & L3 - Joaquim não iria pensar no poder calorífico... Acho que realmente ele só iria pensar no preço do combustível e só. \\
\hline 4 & M2 - Mas e aí... \\
\hline 5 & L3 - Mas aqui a pergunta é: 'os fatores que nós devemos levar em consideração ou Joaquim?' \\
\hline 6 & M2 - Vocês! \\
\hline 7 & $\begin{array}{l}\text { L3 - O que a gente poderia dizer para Joaquim né?! Joaquim, amigo senta aqui vamos conversar... Aí são esses fatores que eu falei } \\
\text { agora, poder calorífico, a entalpia de combustão, os impactos ambientais, o preço, o preço também tem que pensar no preço... }\end{array}$ \\
\hline 8 & $\begin{array}{l}\text { L1- Mas aí se for pensar nisso aí vai ter coisa que vai chocar e ele não vai conseguir comprar nada porque não vai existir uma coisa } \\
\text { 'mix tudo' tá ligado? Ele vai precisar escolher (algum ponto) como prioridade. O que é que a gente vai dizer que ele tem que escolher } \\
\text { como prioridade, é isso que a gente tem que ver. Vamos fingir por um minuto que a gente não é capitalista, se pintar de vermelho } \\
\text { por um minuto e vamos fingir que a gente é comunista. }\end{array}$ \\
\hline 9 & L3 - Acho que a gente poderia elencar três fatores... \\
\hline 10 & L4 - Impacto ambiental, preço... \\
\hline 11 & $\begin{array}{l}\text { L3 - Impacto ambiental, a questão do... Da questão energética porque aí a gente tem que pensar no desenvolvimento do motor, } \\
\text { porque aí não vale a pena a gente comparar uma coisa que move pouco para consumir mais. Aí a gente vai gastar... }\end{array}$ \\
\hline 12 & L2 - A questão econômica. \\
\hline 13 & L3 - Que aí vai influenciar na questão econômica... \\
\hline 14 & L2 - Isso aí é a questão econômica. \\
\hline 15 & L3 - Mas eu estou falando tipo, a gasolina vai queimar vai liberar uma energia maior que a do álcool certo?! \\
\hline 16 & L2 - Sim. \\
\hline 17 & L3 - Só que ela é mais cara que o álcool certo? \\
\hline 18 & L2 - Sim. \\
\hline 19 & $\begin{array}{l}\text { L3 - São coisas diferentes que chegam na mesma coisa; tipo, por mais que a gasolina seja mais cara ela vai fazer mais quilometragem } \\
\text { em menos... }\end{array}$ \\
\hline 20 & L2 - Isso aí não é economia não? \\
\hline 21 & $\begin{array}{l}\text { L3 - É. Só que para ele... Ele não vai entender... Ele vai achar que economia é só o preço da gasolina e o preço do álcool, está } \\
\text { entendendo? O preço lá no visor e não no desenvolvimento. }\end{array}$ \\
\hline 22 & L2 - Não, mas isso aí ele vai saber que a gasolina é mais cara, mas ela rende mais. \\
\hline 23 & L3 - Nem todo mundo sabe! \\
\hline 24 & L2 - Sabe sim! \\
\hline 25 & L3 - Sabe não! \\
\hline 26 & L2 - Sabe! \\
\hline 27 & $\begin{array}{l}\text { L5 - Acho que essa ideia do preço tabelado que você vai pagar litro e litro, tanto e tanto já é mais de antigamente; a galera hoje já tá } \\
\text { visando a economia e a produção... E a quantidade de etanol... A capacidade, eles já estão correndo atrás de saber... }\end{array}$ \\
\hline 28 & M2 - É o rendimento mesmo. \\
\hline
\end{tabular}

Fonte: Dados da pesquisa.

parecem ser compartilhados por vários licenciandos, sobretudo quando questões econômicas e ambientais são consideradas. Isso sugere a reprodução de ideias que circulam nas mídias ou em conversas informais que ocorrem em contextos sociais.

Com a ajuda do texto, houve maior diversificação de ideias nas justificativas dadas pelos licenciandos e parece ter sido estabelecido um processo de negociação de sentidos e significados entre eles. Por exemplo, são mencionadas: questões ambientais (turnos 1, 7 e 10); questões econômicas relacionadas com o preço dos combustíveis (turnos 1,3,7,10, 17 e 21), e questões ideológicas (turno 8). Verificamos que os licenciandos apresentaram dificuldades de se situarem quanto ao problema a ser resolvido, quando eles buscaram definir se falavam por si ou em nome de Joaquim (personagem criado na situação). E, para a discussão de alguns pontos, eles usaram uma terceira pessoa como forma de não explicitar as suas próprias subjetividades (ver turnos 5, 7, 19, 21, 22 e 28). Isso pode se caracterizar como uma dificuldade em expressar seus pontos de vista, valores e 
crenças para os colegas, principalmente neste caso, em que o grupo é formado de licenciandos de vários períodos, ou seja, os participantes do grupo não fazem parte de uma mesma turma.

Diferentemente do que foi observado no episódio 1, no episódio 2, os licenciandos mobilizaram diferentes conceitos químicos na discussão. Alguns itens temáticos foram marcados, tais como, questão energética (turno 11), energia (turno 15), poder calorífico (turnos 1, 3 e 7), entalpia de combustão (turnos 1 e 7), rendimento (turno 28), a comparação entre combustíveis a partir da energia liberada (turnos 15 e 22), entre outros. Esses aspectos foram listados juntamente com menções a questões ambientais (turnos 7 e 10) e econômicas (turnos 11, 22 e 27), ratificando a natureza interdisciplinar e a potencialidade de articulação entre as bases científicas e outras formas de conhecimento fronteiriças à ciência/química (Ratcliffe e Grace, 2003). É importante ressaltar, que no curto tempo do minicurso (4 h), não havia a expectativa de que esses conceitos fossem abordados em maior nível de complexidade. No entanto, em uma situação de aulas regulares, as conexões feitas pelos estudantes podem criar oportunidades para uma discussão mais complexa e articulada dos conceitos científicos. Por exemplo, articulando a questão energética e de combustíveis a aspectos políticos e ideológicos, conforme sugerido no turno 8 (L1), no qual o licenciando associa uma posição a ser tomada a pensamentos capitalista ou comunista.

Após a discussão do texto, os licenciandos fizeram uma sistematização das ideias discutidas em uma ficha de resposta que deveria trazer o posicionamento final do grupo. A ficha de resposta do grupo trazia o seguinte texto:

"A resposta do grupo foi pela compra do carro com motor flex. Porque ele possibilita o uso de duas fontes de energia que prejudicam menos ao ambiente, se comparados ao diesel. Os fatores que deveriam ser considerados seriam: ambiental, poder calorífico, entalpia de combustão e econômico. $O$ álcool e o diesel podem sim substituir a gasolina, porém no caso do diesel não é muito viável por conta de que o mesmo agride mais o ambiente. Na busca por novas fontes de energia, devem ser considerados os mesmos fatores que Joaquim deveria levar em consideração no momento da compra, tendo um olhar mais crítico para a origem da fonte de energia, quanto à questão ambiental”.

$\mathrm{Na}$ resposta escrita pelo grupo, verificamos que as ideias foram bem articuladas no sentido de justificar a escolha do carro que Joaquim deveria comprar. A decisão parece ter sido tomada levando em conta o menor impacto ambiental - aqui, ressaltamos um ponto importante: os licenciandos parecem ter concluído que todos os combustíveis usados nos diferentes tipos de motor causam algum tipo de impacto ambiental e que a escolha seria feita considerando aquele que traria menor impacto. Se somente esse aspecto fosse considerado, o etanol seria apontado como o melhor combustível a ser usado no motor flex, mas essa observação não foi explicitada na resposta. Ao mencionar que foram considerados os aspectos do poder calorífico e entalpia de combustão dos combustíveis, provavelmente os licenciandos estavam se referindo aos valores observados em duas tabelas apresentadas no texto lido - uma que mostrava o poder calorífico, em termos de calor produzido, e outra que trazia a entalpia de combustão de vários combustíveis. Os licenciandos puderam constatar que, em termos de produção de calor, a gasolina seria o melhor combustível a ser usado (entalpia de combustão $=-48.000 \mathrm{~kJ} / \mathrm{kg}$ ), seguido pelo diesel (entalpia de combustão $=-45.000 \mathrm{~kJ} / \mathrm{kg}$ ) e o etanol (entalpia de combustão $=-27.000 \mathrm{~kJ} / \mathrm{kg}$ ). No entanto, eles consideraram o maior impacto ambiental causado pelo diesel e o etanol foi considerado como uma opção mais viável, ainda que apresente menor entalpia de combustão. Apesar de ter sido muito comentado no episódio 2 , o preço não foi mencionado na síntese da resposta. Isso sugere que os licenciandos optaram por não expor algumas ideias que circularam fortemente na discussão (ver turnos 3,7 e 21) e que muitas vezes predominam no contexto social, quando pessoas optam por adquirir carro com motor movido a diesel, por questões econômicas (menor preço).

Alguns possíveis conflitos relativos aos diferentes aspectos considerados pelo grupo na escolha no carro a ser comprado por Joaquim foram expostos na apresentação do grupo, como mostramos no trecho do episódio 3.

No episódio 3, o representante do grupo (L3) mencionou algumas das ideias discutidas e justificou as respostas dadas pelo grupo às questões. Na fala de L3, aparecem termos e expressões que não estavam na ficha com a resposta escrita - por exemplo, "diesel vai liberar metais pesados", a "composição mesmo do combustível" (sic) (turno 3) - mas que estavam nos textos complementares e foram comentadas na discussão. Além disso, podemos verificar que o preço é mencionado na apresentação (turno 1), ainda que não tenha aparecido na resposta escrita. A supressão de questões sobre o preço na resposta escrita sugere que o grupo adotou uma postura de não expor possíveis conflitos subjetivos, nos quais estão envolvidas questões de valores ou de ausência de conhecimento científico, conforme colocado: "Isso para a gente fica mais claro porque a gente já tem um certo conhecimento 'químico', mas para uma pessoa que não teria acesso a essas informações não seria uma coisa tão simples, digamos assim... de pensar" (turno 3). A declaração do licenciando parece apontar para a existência de diferentes pontos de vista sobre a situação proposta, mas sem a pretensão de fazer alguma articulação explícita sobre eles, e isso pode dificultar a reflexão sobre valores e atitudes (Guimarães et al., 2010; Guimarães, 2011; Sadler e Zeidler, 2005), por exemplo, alguns licenciandos expressaram a importância que o preço do combustível teria nas escolhas dos sujeitos, no contexto social (ver episódios 1 e 2).

Ao analisar as interações discursivas que os licenciandos 


\begin{tabular}{|l|l|l|}
\hline 1 & $\begin{array}{l}\text { L3 - Boa noite pessoal, nós ficamos também com a discussão sobre o álcool, a gasolina e o diesel no caso.... E o tema é esse aqui: } \\
\text { 'gasolina e outros combustíveis e tivemos duas situações das quais (apresentamos) a primeira: trata-se da escolha na compra de um } \\
\text { carro, onde o motor seria um a diesel, um a gasolina ou um flex. E nesse caso, na nossa discussão, nós achamos que a melhor opção } \\
\text { para o Joaquim, que é o rapaz que estava querendo comprar esse carro, seria o flex... Acho que o grupo anterior também comentou } \\
\text { a questão da diversidade de fontes energéticas né... Para ser explorada. E aí outra... indagação, né, que teve na situação: 'quais os } \\
\text { fatores que deveriam ser levados em conta...em consideração no momento da compra?' aí discutimos também e podemos concluir que } \\
\text { se deve levar em consideração a questão do poder energético do combustível, os impactos ambientais, a questão econômica, a } \\
\text { questão do preço. E o que mais? }\end{array}$ \\
\hline 32 - Só... \\
\hline $\begin{array}{l}\text { L3 - Só isso, né? A questão da entalpia de combustão também... Isso para a gente fica mais claro porque a gente já tem um certo } \\
\text { conhecimento 'químico', mas para uma pessoa que não teria acesso a essas informações não seria uma coisa tão simples, digamos } \\
\text { assim... de pensar. Aí nem todo mundo quando vai comprar um carro pensaria dessa forma... Aí a outra questão é: 'o etanol e o diesel, } \\
\text { se eles são combustíveis que podem ser substituídos pela gasolina... Aí a gente viu que sim, ele pode, no ponto de vista de combustível, } \\
\text { ele pode sim ser substituído, mas que não é tão relevante por conta das questões ambientais né?...A gente viu durante o texto de } \\
\text { apoio que a gasolina polui um pouco mais do que o álcool e que o diesel polui bem mais do que esses dois... Que aí tem a questão } \\
\text { da... Composição mesmo do combustível, porque na composição do diesel vai liberar metais pesados, vai liberar metais pesados, } \\
\text { enquanto que na gasolina e o álcool não... Vai liberar o co }{ }_{2} \ldots \text { E aí a última pergunta da situação } 1 \text { é: 'quais os fatores que deveriam } \\
\text { ser analisados ao procurar uma nova fonte de energia?' aí a gente discutiu e viu que são as mesmas anteriormente faladas... Só que } \\
\text { com um enfoque maior nas questões dos impactos ambientais e se a fonte seria renovável ou não. }\end{array}$ \\
\hline
\end{tabular}

Fonte: Dados de pesquisa.

estabelecem ao longo de todo o processo culminando com a tomada de decisão pelo motor flex, é possível identificar, nas falas dos licenciandos, critérios que justificaram a decisão tomada coletivamente, são eles: científicos, ambientais, econômicos e/ou políticos, sociais e subjetivos, e tecnológicos. No Quadro 2, ilustramos cada um dos critérios considerados, marcamos itens temáticos e sugerimos alguns compromissos associados às falas dos licenciandos. Vale salientar que os itens temáticos grifados em negrito aparecem em outros turnos ao longo da discussão, principalmente dos episódios 1 e 2.

Com base nos dados e na síntese apresentada no Quadro 2, construímos um diagrama temático referente à decisão tomada pelo grupo, como mostrado na Figura 1. No diagrama temático, os itens temáticos estão representados com letras maiúsculas e as relações semânticas com letras minúsculas.

Entre os itens temáticos (IT) destacamos: a DIVERSIDADE DE FONTES (DE ENERGIA) (citado nos episódios 1, 2, 3 e ficha de resposta) que estabelece uma relação semântica identificado/ identificador com o IT ÁlCOOL (ETANOL)/GASOLINA (episódios 1, 2,3 e ficha de resposta) que, por sua vez, estabelece com outros quatro itens temáticos uma relação semântica de coisa/atributo: com o IT ENTALPIA DE COMBUSTÃo/VOLÁTIL/PODER CALORÍFICO (episódios 2, 3 e ficha de resposta), com o IT PREÇo (citado no episódio 1, 2 e 3), com o IT RENDIMENTO (DO MOTOR) (citado no episódio 2) e com o IT COMPOSIÇÃo (QUíMICA) DO COMBUSTÍvEL (episódio 3). O IT PODER CALORÍFICO estabelece uma relação semântica de sinônimos com o IT PODER ENÉRGÉTICO. O IT DIVERSIDADE DE FONTE ENERGÉTICA também estabelece uma relação semântica de classificador/tipo com o IT FONTES RENOVÁvEIS DE ENERGIA (episódio 2) que estabelece uma relação semântica de agente/processo como IT TRANSFORMAÇÃO SOCIAL (episódio 2).
O IT QUeSTÕES AMBIENTAIS (episódio 1, 2,3 e ficha de resposta) estabelece duas relações semânticas: de conjunto/subconjunto com o IT POLUIÇÃO/LIBERAÇÃO DE CO 2 /DIESEL (episódio 2 , 3 e ficha de resposta), o IT LIBERA METAIS PESADOS (episódio 3) e com o IT impactos AMBIENTAIS (episódio 1, 2,3 e ficha de resposta) e uma relação semântica de sinônimos com QUESTÕES AMBIENTAIS. E por fim, o IT POLUIÇÃo/LIBERAÇão DE $\mathrm{CO}_{2} /$ DIESEL estabelece relação semântica de coisa/quantificador com os IT o ÁLCOOL POLUI MENOS QUE A GASOLINA/O DIESEL POLUI MAIS QUE O ÁLCOOL OU A GASOLINA (episódio 2).

Considerando as relações semânticas que os itens temáticos presentes nas falas dos licenciandos guardam entre si, o diagrama revela que o grupo pauta sua decisão considerando a diversidade energética, isto é, a utilização do etanol ou da gasolina e seus atributos como substâncias combustíveis - poder energético, entalpia de combustão, volatilidade, composição química, rendimento e preço - sendo que a análise para a gasolina está predominantemente pautada no maior poder calorífico e rendimento e, para o etanol, prevalecem o menor impacto ambiental e o menor preço.

No âmbito da diversidade de energia, para os licenciandos a opção por fontes renováveis de energia representaria um processo de transformação social mais efetivo. Dessa forma, eles ressaltam a importância de considerar questões/impactos ambientais (tratados como sinônimos na fala dos licenciandos) - como poluição atmosférica, liberação de $\mathrm{CO}_{2}$ e de metais pesados - na escolha de combustíveis, buscando comparar quantitativamente os impactos causados por cada um - o álcool polui menos do que a gasolina, e o diesel polui mais do que o álcool e a gasolina. Consideramos importante ressaltar o uso do termo álcool - denominação de um grupo funcional de 


\begin{tabular}{|c|c|c|}
\hline Critérios & Turnos/Enunciados & Compromissos \\
\hline Ambientais & $\begin{array}{l}\text { Turno } 17 \text { (episódio 1): L3 - E aí tem a questão da poluição também né, que até } \\
\text { mesmo os textos de apoio eles trazem que o álcool polui menos que a gasolina. Ai } \\
\text { a gasolina que consequentemente polui menos do que o diesel. O diesel nessa } \\
\text { questão aqui a gente nem pensaria! } \\
\text { Turno } 244 \text { (episódio } 2 \text { ): L3 - Os fatores ambientais também né, o poder calorífico, } \\
\text { entalpia de combustão... era só colocar rendimento energético. } \\
\text { Turno } 246 \text { (episódio 2): L3 - Com certeza! Aí é: questões ambientais e econômicas } \\
\text { e os impactos ambientais e preços. } \\
\text { Turno } 249 \text { (episódio 2): L2 - Ambiental?! } \\
\text { Turno } 273 \text { (episódio 2): L1 - Vai ser basicamente impactos ambientais, como isso } \\
\text { vai agredir. Se a fonte é renovável ou não. }\end{array}$ & $\begin{array}{l}\text { Os licenciandos associam } \\
\text { outros conhecimentos } \\
\text { (impactos ambientais) à } \\
\text { decisão. A discussão parece } \\
\text { ser guiada por questões } \\
\text { de valor e cuidado com } \\
\text { o ambiente - surgem } \\
\text { compromissos ontológicos } \\
\text { e axiológicos, além dos } \\
\text { epistemológicos. }\end{array}$ \\
\hline $\begin{array}{l}\text { Econômicos e/ou } \\
\text { Políticos }\end{array}$ & $\begin{array}{l}\text { Turno } 19 \text { (episódio 1): L4- Álcool é um dos mais baratos em relação a gasolina! } \\
\text { Turno } 20 \text { (episódio 2): L3 - É exatamente! Só que a segunda questão, a segunda } \\
\text { contextualização já traz essa questão da economia que a gente pode depois ver, } \\
\text { que mesmo sendo mais barato às vezes não compensa... } \\
\text { Turno } 36 \text { (episódio 2): L3 - Preço. Mas aí é que tá, eles não sabem essa parte da... } \\
\text { da....da energia que é liberada numa determinada massa... tá entendendo? para poder } \\
\text { fazer essa comparação! Eles realmente vão olhar o preço, uma vez ou outra vai colocar } \\
\text { gasolina, para tipo sei lá... não danificar o motor ou alguma coisa do tipo. } \\
\text { Turno } 45 \text { (episódio 2): L1 - Só que a gente tá num sistema que não dá para usar fontes } \\
\text { renováveis onde o custo é maior do que o que eles vão receber como lucro! } \\
\text { Turno } 246 \text { (episódio 2): L3 - Com certeza! Aí é: questões ambientais e econômicas } \\
\text { e os impactos ambientais e preços. }\end{array}$ & $\begin{array}{l}\text { Os licenciandos incluem na } \\
\text { discussão a questão do preço } \\
\text { dos combustíveis e apontam } \\
\text { para implicações econômicas } \\
\text { e políticas. E ainda sugerem } \\
\text { que os aspectos científicos } \\
\text { são pouco conhecidos. A } \\
\text { decisão aqui parece ganhar } \\
\text { uma dimensão mais subjetiva } \\
\text { e tende a ser feita a partir de } \\
\text { compromissos axiológicos. }\end{array}$ \\
\hline Tecnológicos & $\begin{array}{l}\text { Turno } 106 \text { (episódio 2): L1 - Mas mesmo assim em nível de extração de petróleo é } \\
\text { muito perigoso, muito mais perigoso, pô. Tá ligado? Vê a quantidade de metais que } \\
\text { tem aí. A gente dividiu por área de erosão aí, lá nos Estados Unidos, não no México, } \\
\text { no Golfo do México, sei lá... tá ligado? que quebrou e depois ficou jogando petróleo. } \\
\text { Porque foi a erosão lá que a plataforma... }\end{array}$ & $\begin{array}{l}\text { L1 fala de processos } \\
\text { tecnológicos usados na } \\
\text { extração de petróleo e } \\
\text { de riscos ambientais } \\
\text { (compromissos } \\
\text { epistemológicos) }\end{array}$ \\
\hline
\end{tabular}

Fonte: Dados de pesquisa.

compostos orgânicos - para designar o etanol, um exemplar desse grupo funcional, o que ocorre comumente em contextos escolares e cotidianos.
O Quadro 2 mostra compromissos epistemológicos e axiológicos mobilizados ao longo do processo de tomada de decisão pelos licenciandos. Na escolha pelo motor flex, ao discutir 


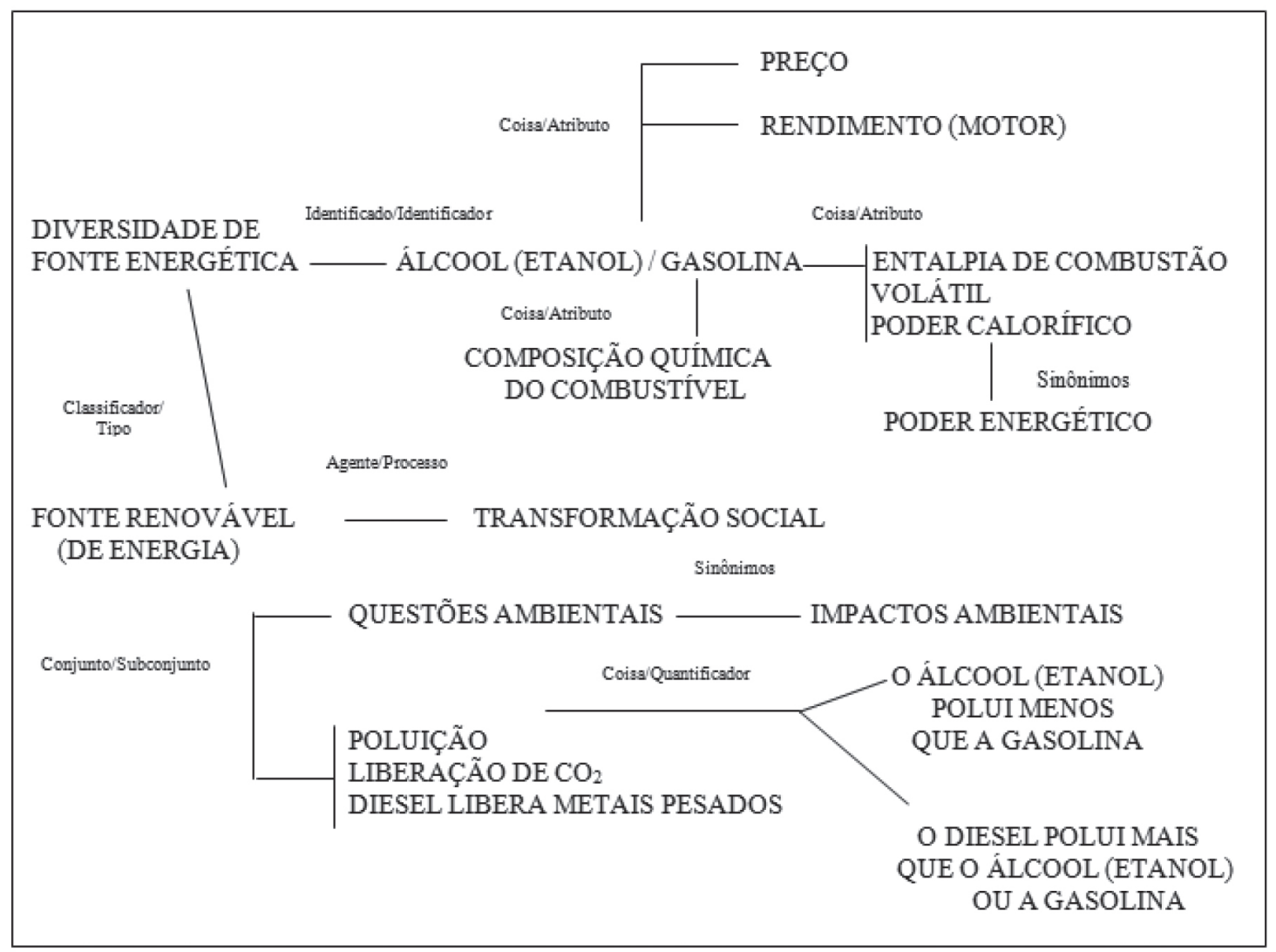

Figura 1: Diagrama de Padrão Temático para a QSC. Fonte: Elaboração própria.

aspectos químicos e físicos relacionados aos combustíveis (critérios científicos), os licenciandos apresentam ideias que trazem um compromisso epistemológico com a decisão a ser tomada. As concepções de combustível parecem associadas às propriedades que eles apresentam - poder calorífico, entalpia de combustão, volatilidade, e rendimento energético - sendo a energia produzida na sua queima um dos parâmetros usados na análise sobre que combustível usar. Ainda que as ideias científicas tenham sido sugeridas pelo texto, elas são adotadas pelos licenciandos e parecem ser representativas de um modo de pensar a energia como funcional e que será utilizada em automóveis (zona funcional/utilitarista do perfil conceitual). Nesse sentido, os critérios científicos são imbuídos de valor pragmático e são usados para justificar a decisão tomada pelo grupo, não obstante outros critérios sejam contrapostos ao longo da discussão.

Ao associar os critérios ambientais à análise, os licenciandos parecem mobilizar, além dos epistemológicos, compromissos ontológicos e axiológicos na discussão sobre a situação proposta. Os itens temáticos que apontam para a construção de significados estão relacionados com: poluição, liberação de $\mathrm{CO}_{2}$ e metais pesados, possibilidade de renovação das fontes e impactos ambientais. Os modos de pensar sobre a energia envolvida no uso de combustíveis parecem se mover de uma perspectiva de utilidade para a possibilidade de causar danos ao ambiente - isso pode representar uma mudança ontológica na qual energia passa a ser prioritariamente considerada como agente que causa transformação no ambiente (outra zona do perfil conceitual), ao invés de produto da queima de combustíveis (algo material). Em geral, discussões sobre impactos ambientais trazem implicadas questões de valor e forte apelo emocional, que muitas vezes circulam nos contextos social e educacional influenciando o modo como as pessoas constroem valores e comportamentos sociais, neste caso, voltados para a preservação ou conservação do ambiente. Nesse sentido, os licenciandos expressaram ideias que traziam alguns compromissos axiológicos, quando posições foram pautadas em valores subjetivos para a tomada de decisão (“...se pintar de vermelho por um minuto..." - episódio 2, turno 8).

Quanto a aspectos econômicos e/ou políticos, os compromissos axiológicos parecem prevalecer para a escolha do melhor combustível, os combustíveis e toda questão energética passam a ser tratados como mercadoria (commodity). Valores de comercialização (preço) e escolhas de fontes energéticas, para alguns licenciandos, são vinculados a opções ideológicas (capitalista e comunista) que orientam os sistemas econômicos e, para outros, esses parâmetros devem estar interligados, por exemplo, ao rendimento do motor. Dessa forma, alguns licenciandos apontaram o preço como algo que seria considerado por muitos usuários como único parâmetro de escolha (compromisso axiológico), outros ponderam que conceitos científicos, como poder calorífico e rendimento energético, podem tornar a decisão mais correta para obter maiores benefícios (compromisso epistemológico). No que se refere aos modos de pensar 
a energia, não encontramos uma zona específica do perfil de energia na qual essa ideia fosse considerada e podemos fazer uma aproximação com um modo de pensar a energia como algo material (um produto a ser comercializado). Nesse sentido, Simões Neto e Amaral (2013) apontam para possibilidades de ampliação do perfil proposto para energia, considerando contextos diversos.

Os critérios sociais, ou seja, que implicam em mudanças sociais mais amplas, foram discutidos de forma tímida ao longo do minicurso. Um dos licenciados mencionou que mudanças na política de uso dos combustíveis, buscando diminuir efetivamente impactos ambientais, trariam uma transformação social, mas não explicitou o que queria dizer com transformação social. Nesse caso, identificamos um compromisso axiológico no qual poderiam ser adotados valores individuais que visam benefícios sociais mais amplos, principalmente associado à opção por fontes renováveis de energia. Nesse sentido, o modo de pensar sobre energia parece estar relacionado com o seu uso e funcionalidade a partir de uma preocupação com o bem-estar social. Da mesma forma, em um momento específico da discussão do grupo, foram mencionados aspectos sobre a tecnologia de extração do petróleo e impactos ambientais (critérios tecnológicos), no qual identificamos um compromisso epistemológico. Um licenciando alertou para os impactos ambientais associados à obtenção de combustíveis a partir do petróleo, usou exemplos de outros países (México e Estados Unidos), mas esses aspectos não foram retomados na discussão do grupo. Aqui, a extração do petróleo como matéria-prima para a produção de energia parece trazer uma ideia de energia como produto material (energia com algo material).

Na Figura 2, sistematizamos compromissos e modos de pensar identificados na análise.
Em síntese, ao abordar a QSC pudemos verificar que a discussão inicialmente pautada em ideias vagas, impressões e conhecimentos do senso comum se ampliou e foi enriquecida a partir da introdução da leitura de um texto de apoio que trouxe informações principalmente sobre características físicas e químicas, e questões ambientais relacionada com a produção e uso de combustíveis. No processo de negociação de sentidos e construção de significados pelos licenciandos foram mobilizados compromissos epistemológicos, ontológicos e axiológicos, o que confirma o potencial de uma QSC para a complexificação do conhecimento cotidiano, com a incorporação e articulação de novos conhecimentos (Rodrigues e Mattos, 2007), possibilita que a dimensão axiológica seja explicitamente considerada nas discussões. Acreditamos que a abordagem de QSC construídas de forma a representar contextos diferenciados nos quais possa ser trabalhada a heterogeneidade do pensamento, podem contribuir para significar conceitos científicos, criando articulações com a vida e experiência dos estudantes.

\section{Considerações Finais}

Nossa análise buscou caracterizar diferentes modos de pensar que emergem em falas de licenciandos quando trabalham com questões sociocientíficas, a partir da perspectiva de perfis conceituais, quando contextos exógenos à sala de aula são constituídos. A partir de uma situação contextualizada foi constituído um contexto e colocadas questões para tomada de decisão, em que os conhecimentos científicos não seriam suficientes para esgotar as possibilidades de respostas. Dessa forma, a questão sociocientífica foi usada como forma de promover interações discursivas e explicitar a heterogeneidade do pensamento verbal com relação

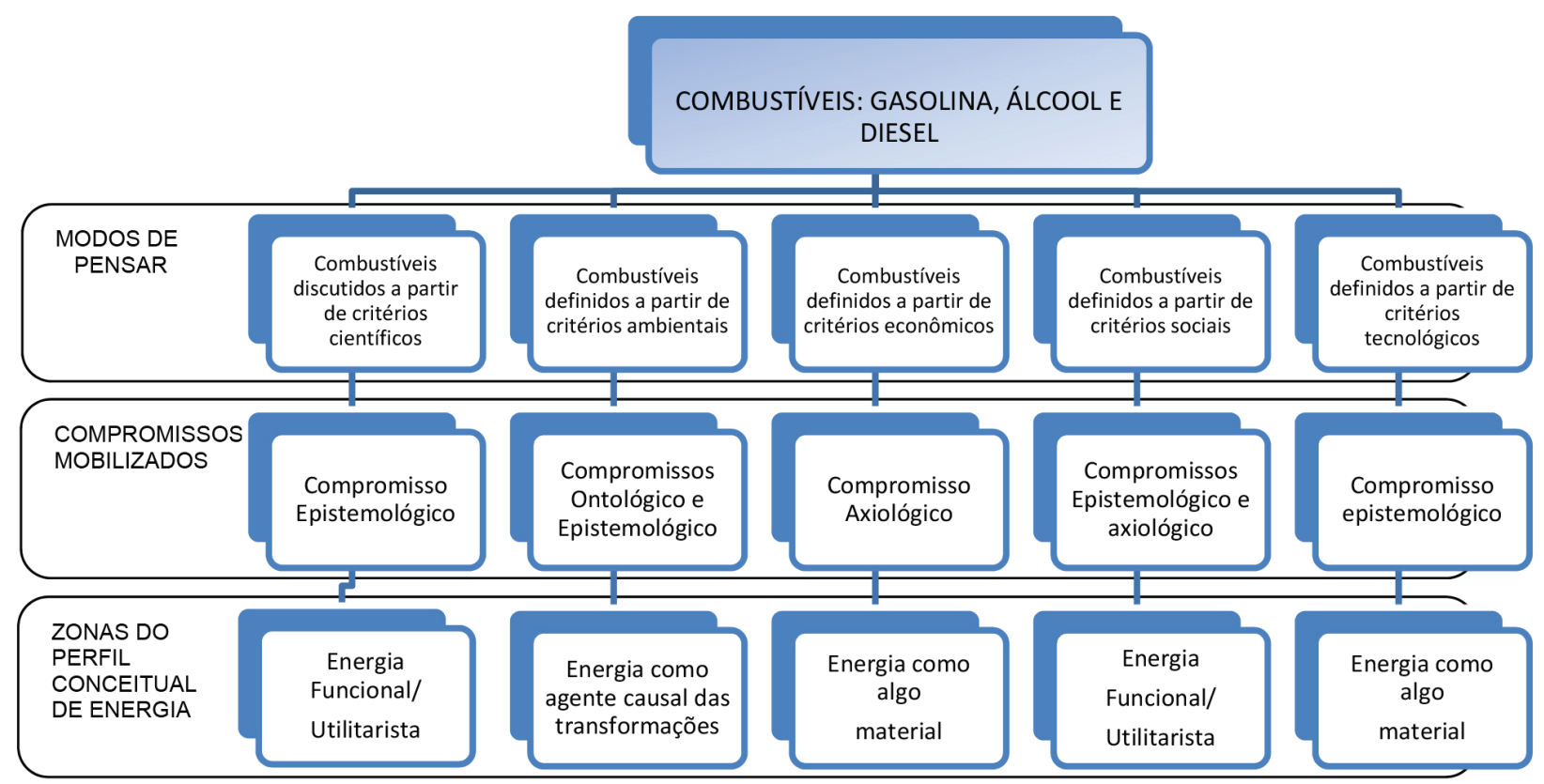

Figura 2: Sistematização de modos de pensar sobre combustíveis e os compromissos epistemológicos, ontológicos e axiológicos mobilizados. Fonte: Elaboração própria. 
à temática abordada. Na discussão da QSC os licenciandos se engajaram num processo de negociação de sentidos e construção de significados em que foram mobilizados diferentes modos de pensar associados a compromissos epistemológicos, ontológicos e axiológicos, implicados no processo de tomada de decisão sobre a situação proposta. Ao se referir aos combustíveis, seus atributos e propriedades, preço, rendimento e possíveis impactos ambientais, os licenciandos expressaram ideias sobre combustíveis e energia. Ainda que a decisão não tenha sido conflituosa, houve maior complexidade na construção das justificativas pelo fato de o tema ser tratado a partir de múltiplos olhares (científicos e não científicos).

\section{Referências}

AMARAL, E. M. R. e MORTIMER, E. F. Uma metodologia para análise da dinâmica discursiva entre zonas de um perfil conceitual no discurso da sala de aula. In: SANTOS, F. M. T. e GREGA, U. I. M. (Orgs.). A pesquisa em ensino de ciências no Brasil e suas metodologias. Ijuí: Editora Unijuí, 2006, p. 239-296. (Coleção Educação em Ciências).

e __. Uma proposta de perfil conceitual para o conceito de calor. Revista Brasileira de Pesquisa em Educação em Ciências, v. 1, n. 3, p. 1-16, 2001.

e __. Un perfil conceptual para entropía y espontaneidad: una caracterización de las formas de pensar y hablar en el aula de química. Educación Química, n. 3, p. 60-75, 2004.

ANDRÉ, M. Questões sobre os fins e sobre os métodos de pesquisa em educação. Revista Eletrônica de Educação, v. 1, n. 1, p. 119-131, 2010.

ARAÚJO, A. O. e MORTIMER, E. F. A utilização do conceito de calor por bombeiros militares e técnicos em refrigeração de ambientes. In: Anais do IX Encontro Nacional de Pesquisa em Educação (ENPEC). Águas de Lindóia, SP, 2013.

BAKHTIN, M. Marxismo e filosofia da linguagem. 7a ed. São Paulo: Hucitec, 1929/1995.

BASTOS, P. W. e MATTOS, C. R. Um exemplo da dinâmica do perfil conceitual como complexificação do conhecimento cotidiano. Revista Electrónica de Enseñanza de las Ciencias, v. 8, n. 3, p. 1054-1078, 2009.

CHI, M. T. H. Conceptual change within and across ontological categories: examples from learning and discovery science. In: GIERE, R. N. (Ed.). Cognitive models of science (Minnesota studies in the philosophy of science, vol. XV). Minneapolis: University of Minnesota Press, 1992.

DRIVER, R.; NEWTON, P. e OSBORNE, J. Establishing the norms of scientific argumentation in classrooms. Science Education, v. 84, n. 3, p. 287-312, 2000.

FREIRE, M. S. Perfil conceitual de química: contribuições para uma análise da natureza da química e do seu ensino. Tese (Doutorado em Ensino das Ciências). Universidade Federal Rural de Pernambuco, Recife, 2017.

GALVÃO, C. e REIS, P. A promoção do interesse e da relevância do ensino da ciência através da discussão de controvérsias sociocientíficas. In: VIEIRA, R. M.; PEDROSA, M. A.; PAIXÃO, F.; MARTINS, I. P.; CAAMAÑO, A.; VILCHES, A. e MARTÍNDIAZ, M. J. (Coords.). Ciência-tecnologia-sociedade no ensino das ciências: educação científica e desenvolvimento sustentável. Aveiro: Universidade de Aveiro, 2008, p. 131-135.

GUIMARÃES, M. A. Raciocínio informal e a discussão de questões sociocientíficas: o exemplo das células-tronco humanas. Tese (Doutorado em Educação para a Ciência). Universidade Estadual Paulista, Bauru, 2011. Disponível em http://hdl.handle. net/11449/102068, acessada em Janeiro 2019.

; CARVALHO, W. L. P. e OLIVEIRA, M. S. Raciocínio moral na tomada de decisões em relação a questões sociocientíficas: o exemplo do melhoramento genético humano. Ciência \& Educação, v. 16, n. 2, p. 465-477, 2010.

HALVERSON, K. L.; SIEGEL, M. A. e FREYERMUTH, S. K. Lenses for framing decisions: undergraduates' decision making about stem cell research. International Journal of Science Education, v. 31, n. 9, p. 1249-1268, 2009.

LEMKE, J. L. Cognition, context, and learning: a social semiotic perspective. Situated Cognition: Social, Semiotic, and Psychological Perspectives, p. 37-56, 1997.

MARTÍNEZ PÉREZ, L. F. M. e CARVALHO, W. L. P. Contribuições e dificuldades da abordagem de questões sociocientíficas na prática de professores de ciências. Educação e Pesquisa, v. 38, n. 3, p. 727$741,2012$.

MORTIMER, E. F. Conceptual chance or conceptual profile chance? Science Education, v. 4, n. 3, p. 265-287, 1995.

Linguagem e formação de conceitos no ensino de ciências. Belo Horizonte: Ed. UFMG, 2000.

Para além das fronteiras da química: relações entre filosofia, psicologia e ensino de química. Química Nova, v. 20, n. 2, p. $200-$ 207, 1997.

e AMARAL, L. O. F. Contributions of the sociocultural domain to build a conceptual profile model for molecule and molecular structure. In: MORTIMER, E. F. e EL-HANI, C. N. (Eds.). Conceptual profiles: a theory of teaching and learning scientific concepts. New York: Springer, 2014.

e EL-HANI, C. N. Uma visão sócio-interacionista e situada dos conceitos e a internalização em Vygotsky. In: Anais do IX Encontro Nacional de Pesquisa em Educação em Ciências. Águas de Lindoia, SP, 2013.

e SCOTT, P. Atividade discursiva nas salas de aula de ciências: uma ferramenta sociocultural para analisar e planejar o ensino. Investigações em Ensino de Ciências, v. 7, n. 3, p. 283-306, 2002. ; AMARAL, E. M. R. e EL-HANI, C. N. Conceptual profiles: theoretical-methodological bases of research program. In: MORTIMER, E. F. e EL-HANI, C. N. (Eds.). Conceptual profiles: a theory of teaching and learning scientific concepts. New York: Springer, 2014, p. 3-33.

e WERTSCH, J. V. The architecture and dynamics of intersubjectivity in science classrooms. Mind, Culture, and Activity, v. 10, n. 3, p. 230-244, 2003. 
POMPE, S.; BADER, M. e TANNERT, C. Stem-cell research: the state of the art. EMBO Reports, v. 6, n. 4, p. 297-300, 2005.

RATCLIFFE, M. e GRACE, M. Science education for citizenship: teaching socio-scientific issues. London: McGraw-Hill Education, 2003.

RODRIGUES, A. M. e MATTOS, C. R. Reflexões sobre a noção de significado em contexto. Indivisa, Boletín de Estudios e Investigación, v. 7, p. 323-333, 2007.

RODRIGUES, R. F. e PEREIRA, A. P. Uma análise sociocultural da estrutura de explicações no ensino de física. In: Anais do X Encontro Nacional de Pesquisa em Educação em Ciências (ENPEC). Águas de Lindóia, SP, 2015.

SABINO, J. D. A utilização do perfil conceitual de substância em sala de aula. Dissertação (Mestrado em Ensino das Ciências). Universidade Federal Rural de Pernambuco, Recife, 2015.

e AMARAL, E. M. R. Utilização do perfil conceitual de substância no planejamento do ensino e na análise do processo de aprendizagem. Investigações em Ensino de Ciências, v. 23, n. 1, p. 245-265, 2018.

Zonas do perfil conceitual de substância que emergem na fala de alunos quando envolvidos em diferentes atividades didáticas. In: Anais do X Encontro Nacional de Pesquisa em Educação em Ciências (ENPEC). Águas de Lindóia, SP, 2015.

SADLER, T. D. Informal reasoning regarding socio-scientific issues: a critical review of research. Journal of Research in Science Teaching, v. 41, n. 5, p. 513-536, 2004.

. Situating socio-scientific issues in classrooms as a means of achieving goals of science education. In: SADLER, T. D. (Ed.). Socio-scientific issues in the classroom: teaching, learning and research. Springer, Dordrecht, p. 1 -9, 2011.

e ZEIDLER, D. L. The significance of content knowledge for informal reasoning regarding socio-scientific issues: applying genetics knowledge to genetic engineering issues. Science Education, v. 89, n. 1, p. 71-93, 2005.

SEPÚLVEDA, C. Aplicação de um perfil conceitual para adaptação à análise de interações discursivas no ensino de evolução. In: Anais do VII Encontro Nacional de Pesquisa em Educação em Ciências (ENPEC). Florianópolis, SC, 2009.

; REIS, V. P. G. S.; ALMEIDA, M. C.; CARNEIRO, M. C. L.; AMARANTE, A. L. A. C. P. e EL-HANI, C. N. Uma ferramenta sociocultural de análise da apropriação da linguagem social da ciência escolar. In: Atas do VIII Encontro Nacional de Pesquisa em Educação em Ciências (ENPEC). Campinas, SP, 2011.
SILVA, J. R. R. T. Um perfil conceitual para o conceito de substância. Dissertação (Mestrado em Ensino das Ciências). Universidade Federal Rural de Pernambuco, Recife, 2011.

e AMARAL, E. M. R. Proposta de abordagem para o ensino de reações químicas a partir da noção de perfil conceitual. In: ALBUQUERQUE, U. P.; VERAS, A. S. C.; FREIRE, F. J. e LIRA JÚNIOR, M. A. (Orgs.). Caminhos da Ciência. $1^{\mathrm{a}}$ ed. Recife: EDUFRPE, 2006, v. 1, p. 259-273.

e

. Proposta de um perfil conceitual para substância.

Revista Brasileira de Pesquisa em Educação em Ciências, v. 13, n. 3, p. 53-72, 2013.

SIMÕES NETO, J. E. Uma proposta para o perfil conceitual de energia em contexto do ensino da física e da química. Tese (Doutorado em Ensino de Ciências). Universidade Federal Rural de Pernambuco, Recife, 2016.

e AMARAL, E. M. R. A produção brasileira sobre a noção de perfil conceitual - analisando tendências. In: Anais do IX Encontro Nacional de Pesquisa em Educação em Ciências (IX ENPEC). Águas de Lindóia, SP, 2013.

$\mathrm{e}$ Uma proposta para o perfil conceitual de energia nos contextos do ensino da física e da química. In: Anais do XI Encontro Nacional de Pesquisa em Educação em Ciências (ENPEC). Florianópolis, SC, 2017.

; SILVA, J. R. R. T; CRUZ, M. E. B. e AMARAL, E. M. R. Una secuencia didáctica para abordar el concepto de calor en la enseñanza de estudiantes preuniversitarios. Formación Universitaria, v. 8, n. 2, p. 3-10, 2015.

SODRÉ, F. C. R. Física para uma alimentação saudável. Dissertação (Mestrado em Ensino de Ciências). Universidade de São Paulo, São Paulo, 2008.

e MATTOS, C. R. Complexificando o conhecimento cotidiano: incluindo a física na problematização da alimentação. Alexandria: Revista de Educação em Ciência e Tecnologia, v. 6, n. 2, p. 53-79, 2013.

TULVISTE, P. e HALL, M. J. T. The cultural-historical development of verbal thinking. New York: Nova Science Publishers, 1991.

VYGOTSKY, L. S. Language and thought. Cambridge: MIT Press, 1962. ZEIDLER, D. L.; SADLER, T. D.; SIMMONS, M. L. e HOWES, E. V. Beyond STS: a research-based framework for socio-scientific issues education. Science Education, v. 89, n. 3, p. 357-377, 2005. 